\title{
PSCPF: planning, scheduling and control of patient flow
}

\author{
Thiago A. Souza ${ }^{a *}$ (D), Guilherme L. R. Vaccaro ${ }^{\mathrm{b}}$ (D), Rui M. Lima ${ }^{\mathrm{a}}$ \\ aUniversidade do Minho, Escola de Engenharia, Departamento de Produção e Sistemas, Centro Algoritmi, Guimarães, Portugal \\ bMagna International Inc., Cosma Assembly Technology, Toronto, Canada \\ *thiagosouza.uem@gmail.com
}

\begin{abstract}
Paper aims: lack of operational planning in healthcare organizations may result in service disconnection and reduced value per effort to the patient. Production Planning, Scheduling and Control assists in determining "what," "how much," "when" and "where" to deliver, which may be of great relevance to healthcare services. This study proposes a structural framework and analyzes the implementation of PPSC concepts in OR management.
\end{abstract}

Originality: The application of concepts from manufacturing applied to healthcare as the PPSC, present in this text, demonstrates the crossing and alignment of global management techniques and tools applicable to both areas.

Research method: The discussion is based on data gathered through action-research in a Brazilian public hospital.

Main findings: In the hospital under study, the PSCPF implementation resulted in increased production control of surgeries, increased efficiency in management of waiting lists, increased operational efficiency, and motivational gains from staff integration.

Implications for theory and practice: The understanding and proper implementation of the concept of PPSC contributed to mitigate problems related to capacity management, reduced the unawareness of different levels of demand and waiting lists, cut down scheduling errors, and prevented the provision of false information from the disconnection between the various areas of the hospital.

Keywords

Healthcare management. Lean healthcare. Production planning and control. Patient flow. Operating room.

How to cite this article: Souza, T. A., Vaccaro, G. L. R., \& Lima, R. M. (2021). PSCPF: planning, scheduling and control of patient flow. Production, 31, e20200006. https://doi.org/10.1590/0103-6513.20200006

Received: Jan. 27, 2021; Accepted: Apr. 22, 2021.

\section{Introduction}

Planning plays a vital role in directing the organizational efforts to achieve previously outlined goals. It represents an essential component of Operations Management (OM), establishing bases for meeting demands, and improving service-level and patient-value delivery (Drupsteen et al., 2013).

In healthcare services, a failure in planning processes results in disconnection among sectors, lack of clearly envisioned goals, loss of focus on the patient's well-being, and many wastes, such as late deliveries of supplies, items returned or missing due to improper order management, limited and misused storage space, non-standardized procedures, difficulties in operating new equipment; imbalance of activity loads among employees, turnover due to conflicts and lack of motivation or goals, idleness and inefficiency. All these manifestations of an ineffective process planning impact negatively the value/work ratio. Moreover, the hospital management problems previously mentioned are current but not new; Graban (2009) points out that, in the United States, the Training Within Industry program detected similar problems in the year 1944. 
A fundamental aspect of operations planning is to differentiate occupation from production: while occupation may be translated as work, in healthcare, production is the parcel of work which generates and delivers value to the patient (Graban, 2009). In addressing the problems presented in the previous paragraph, a misunderstanding of these concepts may lead to mainstream solutions, as increasing personnel or the areas' physical capacity, which incur in increased complexity and costs. Thus, each sector conducts its activities in their way, "doing their best", without planning and coordination (Vieira, 2009), ignoring the impacts local optimizations may cause to the healthcare organization's global performance

In a healthcare context, operations planning the main focus is not about reducing the time of adding-value activities, rather reducing the time of non-value-adding activities to the patient, thus increasing the time rate of patient's added-value activities. To do so, operational efficiency, or simply the value/work ratio, and improved patient flow become central subjects of discussion which require operations planning (Dutra \& Erdmann, 2007). In the healthcare context, to improve the patient flow and services operation's efficiency significantly impacts the providers' sustainability through reduced operating costs or increased operational capacity.

Originated from the industry sector, Production Planning, Scheduling and Control (PPSC) concepts support the organization's decisions on "what," "how much," "when" and "where" to produce and about "what," "how much" and "when" to buy (Pedroso \& Corrêa, 1996). It lays in the healthcare organization's middleware, integrating the strategic positioning with the operational dimensions of the value delivered to the patient. Under such perspective, four integrative practices stand out: strategic planning; interdepartmental planning; integrated processes among departments; and sharing waiting-list information. The global level of integration in hospitals was found to be low compared to the integration of the manufacturing industry. However, patientflow performance was shown to be significantly better in hospitals employing more of the above-mentioned integrative practices (Drupsteen et al., 2013), i.e., hospitals that plan value delivery to the patient.

Despite well discussed in the context of industry and certain brands of services, such as banking and aerologistics, the scientific literature is still scarce on the implementation and analysis of PPSC processes in healthcare organizations. Cardoso \& Erdmann (2001) conducted a study to understand the use of PPSC concepts in the emergency room of a Brazilian university hospital. These authors concluded that appropriate tools to manage this type of processes in hospital companies were lacking and that demand, capacity planning, and production control were not found among managers. Another study in the context of the Spanish healthcare system found a significant decrease in waiting-list lengths for surgeries caused by PPSC-related measures: an contract at another hospital (i.e., capacity increase); staff to manage waiting lists in scheduling services; and setting and monitoring deadlines for the realization of preoperative care (Conill et al., 2011). Moreover, a recent systematic review study (Lima et al., 2021) showed a lack of integrated approaches to the global hospital organization, recommending developing research studies on complete flows of patients.

Focusing on institutionalized planning oriented to epidemiology (or demand), following the formulation of strategies with deployment for operations, and considering the multiple dimensions of health services, is a significant change in the field of health management, requiring the inclusion of new processes in hospital practices (Teixeira, 1999), the introduction of such concepts in critical processes of healthcare organizations may produce significant results. Guided by this perception, this article analyzes the applicability of PPSC concepts in healthcare critical services, based on literature review and data gathered from action-research on a large university hospital affiliated to the Brazilian public network. An emerging framework for implementing a sector to manage the flow of elective patients (PSCPF: Planning, Scheduling and Control of Patient Flow) is proposed. Such a framework contributes to overcome the identified research gap regarding the need to develop solutions for integrated and holistic approaches for hospital operations management, which in this case materializes through a proposal to support production planning and control of flow of patients. Additionally, it also contributes to inspire practitioners to implement PPSC concepts to manage the flow of hospital patients.

The next section presents the theoretical background and relevant studies gathered from literature review. The research method is then described, followed by the action-research study description. Finally, the framework proposal is presented and its application in healthcare critical services is discussed, and key remarks are summarized as conclusion.

\section{Production planning, scheduling and control in healthcare}

\subsection{Production planning, scheduling and control}

PPSC is a discipline in the field of OM related to Production and Process Engineering (Associação Brasileira de Engenharia de Produção, 2008). Put in a simple interpretation, its main function is to plan and control 
resources related to the production process to meet customer demand (Slack et al., 1995). PPSC operates at the three hierarchical levels (strategic, tactical and operational), through ideation, planning, operation and control of processes (Lustosa et al., 2008). At the strategic level, PPSC will be responsible for developing long-term policies, planning productive capacity and providing information on the required resources to meet the organization's strategic goals. At the tactical level, PPSC will establish and manage medium-term plans, defining the mix of products or services to be delivered and creating a master production plan. And at the operational level, it will carry out short-term plans to effectively deliver value through products and services, ensuring the fulfill of materials and resources needs, through the control of inventories, production orders, changes in demand, quality alerts, and other daily issues.

In a conceptually integrated manner, the PPSC function is responsible for implementing the production function: coordinating processes and resources in order to ensure efficient and cost-effective flow of value through the organization. This includes: determining how much of each product/service is required to be delivered based on customer orders and/or demand forecasts; planning material requirements, including lot sizing; creating purchase and production orders; scheduling, sequencing and controlling production orders; controlling inventories; planning and balancing capacities; controlling performance; and taking actions in the event of a deviation (Zäpfel \& Missbauer, 1993; Vollmann et al., 2006). The same can be evidenced by hospital organizations: the management of medical and assistance services agenda is a simple, but obvious demonstration of these concepts.

PPSC represents an operational axis of the organization's strategic positioning: any deficiency in this area is projected immediately into the service quality and the customer satisfaction. It may be considered an information processing (Laugeni \& Martins, 2005) and management area, since it receives information from other processes and resources of the organization and transforms it into coordinated production efforts. Such system decisions directly affect the organization's performance measures that are directly perceived by customers, including inventory levels, production capacity utilization and especially, service level (or meeting of the demand). Thinking about these decisions as primary, some dimensions that are usually assessed for PPSC performance evaluation are delivery speed, punctuality, availability and flexibility (Pedroso, 1999). As a consequence, the concepts of efficiency and effectiveness are closely linked to this activity (Dutra \& Erdmann, 2007). Figure 1 shows how PPC (Production Planning and Control or PPSC) decisions impact the company's performance in relation to these dimensions.

As shown in Figure 1, the PPSC function shall balance capacity and demand. Capacity includes supply of materials and resources, efficiency, and processes. As capacity and demand are associated with volatile variables, the PPSC effectiveness should be an ongoing concern in the field of OM (Pontual, 2004).

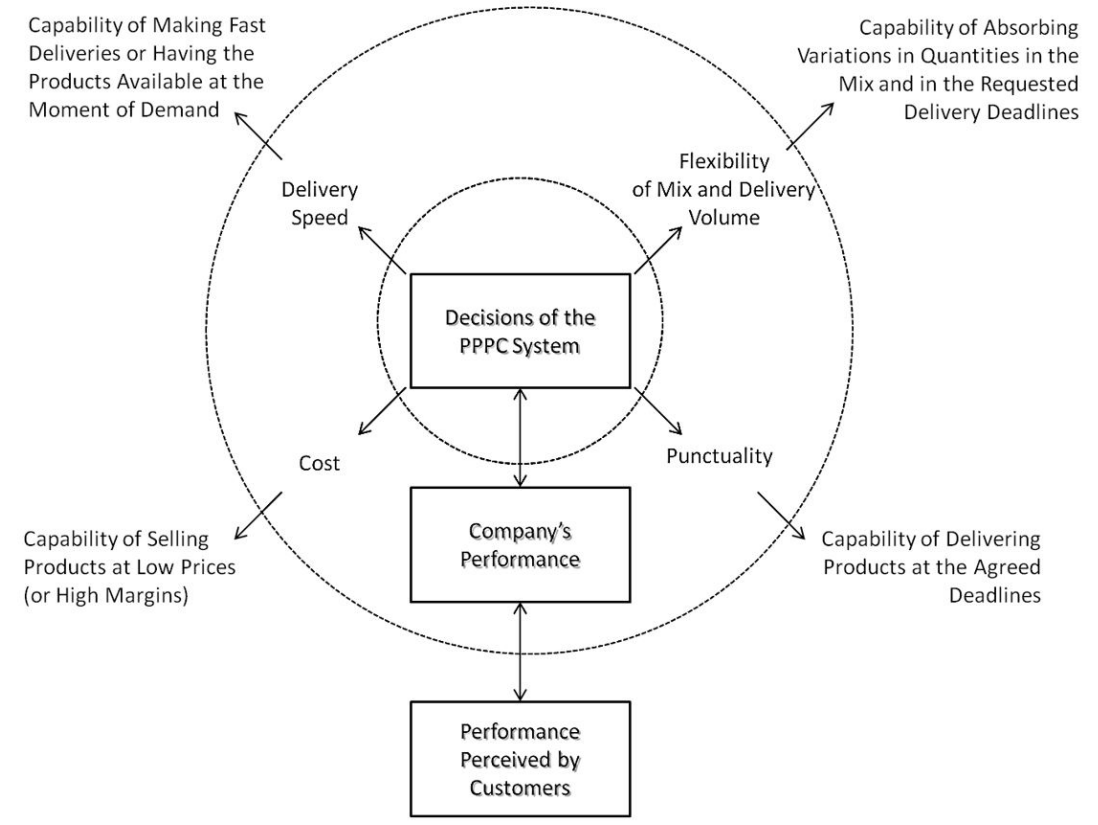

Figure 1. Impacts of PPSC decisions on the organizational performance (adapted from Pedroso, 1999). 


\subsection{Patient flow and efficient operations management in healthcare services}

Patients flow through the healthcare provision system from before admission until discharge (Graban, 2009). Value to the patients is associated with the speedy recovery of their health in the best possible manner. An efficient process planning of value delivery implies ways to generate the value expected by the patient with the least possible effort or creating more value for the effort spent.

While value depends on an organization's ability to creatively invest its capabilities in support of future innovations (Hart \& Milstein, 2004), the value effectively created or delivered relies on planning and monitoring. In addition, control mechanisms must be more complex as the processes to be controlled become more complex (Fernandes \& Santoro, 2005). These arguments are closely linked to the healthcare context, which entails not only complex processes requiring increased control but also higher costs that force daily management innovations. Value is an important concept for improving performance in operations management, however, value in the healthcare industry remains quickly misunderstood. The value must be defined by the customer's voice. It is the value for the patient that is the central objective, it is not the value for other actors in the process. Therefore, planning and control of end-to-end operations with a focus on the patient flow with the most appropriate and efficient programming can affect people-centered care flows (Porter, 2010). In this line of thought, (Hasle et al., 2016) defend the need to define a common value between patients and different hospital professionals, as doctors, nurses, and managers.

Value is closely related to flow, and for that reason it is important to understand different type of flows in hospital context. Thus, one example of a critical patient flow is the surgical one that will be briefly characterized. Additionally, this will be referred in the scope of the intervention later in this article. Surgical patients are typically classified as either elective or non-elective. Non-elective patients are having unexpected surgery that is either urgent (i.e., without risk of imminent death) or an emergency (i.e., with risk of permanent disability or imminent death). Elective patients' surgeries can be planned, and elective patients can be classified as either inpatients or outpatients. Inpatients need to stay one or more nights in the hospital, whereas outpatient would be out of the hospital in less than one day (Cardoen et al., 2010). Even backup hospitals, i.e., those that are not responsible for an emergency room (ER), need to plan capacity for urgent and emergency care, serving as buffers for emergency hospitals. Under normal conditions, however, the larger portion of care involves elective patients, which represents the flow being studied as the scope of this article.

Given the number and complexity of processes along with the amount of resources and people involved in healthcare organizations, improvisation, although unavoidable in real world healthcare operations, should be an insignificant part of the hospital teams' daily effort. In this sense, to plan and control both organizational and assistance processes becomes urgent (Paim, 2006). Healthcare management needs to devote more attention to routine operations related to the patient flow (Souza et al., 2020), thereby structuring long-term planned, medium-term programmed, and daily controlled services (Butler et al., 1996), seeking for: operational efficiency gains to reduce costs; increased quality, speed and reliability on care delivering; and focused innovation to support the healthcare organization's mission and its business strategy of being sustainable in the market.

In the Brazilian context, hospitals are observed to experience many unwanted effects on patient flow. Those effects are typically associated with longer-than-necessary waits, cancellation and excessive rescheduling of procedures, and low level of the service provided to the population compared to the installed capacity (LaGanga, 2011; Conill et al., 2011; Lemos et al., 2013). Such problems are often found in the literature and can be divided into the three perspectives of PPSC. Table 1 compiles reported problems in the health-care context ranked based on the perspective of various operations-management concepts.

Problems related to planning are perceived, including capacity and demand management, a lack of flow management and waiting lists, goal setting, and disintegration between the involved departments. With respect to programming, the errors in the scheduling process, patient information, standardization and agility in routine processes are considered problems by the authors are listed above. Control-related problems relate to the non-monitoring of performance and process performance, in addition to limitations in the information system.

There are several ways that hospitals can mitigate the problems presented in Table 1 and increase the value delivered to patients: reducing the length of stay; increasing the bed occupancy rate; expanding capacity; and expanding personnel (Litvak \& Bisognano, 2011). The two first alternatives involve increasing efficiency and effectiveness and are more desirable in comparison to the latter two, as formerly stated. For this vision to occur in a hospital, in general, a structure and processes are required that are related in a systemic and managerial way with the concepts of PPSC with a focus on the planning and coordination of assistance and support operations, raising such a topic a research gap regarding a holistic framework focused on managing the flow of patients (Cardoso \& Erdmann, 2001; Drupsteen et al., 2013; Lima et al., 2021). 
Table 1. Problems related to Production Planning and Control.

\begin{tabular}{|c|c|c|}
\hline Perspectives & Problems & Authors \\
\hline \multirow{6}{*}{ Planning } & - Low production capacity in relation to demand & LaGanga (2011) \\
\hline & - Flawed management of waiting lists & Lemos et al. (2013) \\
\hline & - Lack of production and quality goals & Lemos et al. (2013) \\
\hline & - Disordered demand flow & Pires et al. (2010) \\
\hline & - Unintegrated departments (silos) & Conill et al. (2011) \\
\hline & & Rechel et al. (2010) \\
\hline \multirow{4}{*}{ Scheduling } & - Scheduling errors & LaGanga (2011) \\
\hline & - Failure in the standardization of procedures and time & Pires et al. (2010) \\
\hline & - Wrong information to the patient & LaGanga (2011) \\
\hline & - Under/Over-utilized structures and delayed processes & Spagnol \& Ferraz (2002) \\
\hline \multirow{4}{*}{ Control } & - Lack of no-show control and cancellations & LaGanga (2011) \\
\hline & · Flawed efficiency control & Ribeiro (1993) \\
\hline & - Limitations in information management & Cima et al.(2011) \\
\hline & - Lack of key performance indicators & \\
\hline
\end{tabular}

\section{Research method}

This paper presents part of the research developed, from December 2015 to October 2017, at a university hospital serving the public healthcare system and located in Southern Brazil. Under public-private management, the hospital is responsible for approximately 500 inpatient beds, 11,000 monthly consultations and 600 monthly surgeries, offering high-, medium- and low-complexity services. The two-year field research was based on the action-research method and, accordingly, the main objective was designed collaboratively with the hospital management and set as 'mitigating problems related to patients' flow management'. Based on this initial objective, the action-research cycles focused on four different areas: operating room (OR) and inpatient unit, the diagnosis and imaging center, the laboratories, and the flow of elective surgical patients (including the outpatient sector). This paper addresses the latter.

The action-research was divided into four phases: (i) exploration and collection of information; (ii) definition of the problem and formulation of the action plan; (iii) execution of the action plan, with participatory and dynamically adjustable activities according to the increase conscience of the problem; and (iv) analysis of results.

Phase (i) started with a brief preliminary diagnosis to create sensibility towards the complexity of the context, as well as to ensure interest and engagement from the managerial board. This activity was based on a previous action-research cycle conducted on the operating rooms that evidenced the size of queues for each medical specialist. Then, literature was researched on the topics: Production Planning, Scheduling and Control, health planning, patient flow, and healthcare operations management. Sources included scientific papers indexed on international databases, and reports on health operations management applied cases from international and Brazilian healthcare associations.

Next, a situational diagnosis was carried out, based on direct observation, in-depth interviews, and documents analysis. Observation was performed on a daily basis, since one of the researchers was spending eight hours a day in the hospital, transitioning among the areas. The inquiry option was to use a qualitative phenomenological approach in this phase, implemented by using narrative interviews based on two open questions: "What are the problems in the flow of elective patients?" and "What are your suggestions to improve this flow?". The main goal was to access the lived experience of the interviewees regarding this specific process and the context elements that they perceived as contributing to the problems faced. To identify interviewees, a purposive sampling was adopted (Welman \& Kruger, 1999), selecting the sample based on the researchers' judgement and the purpose of the research (Schwandt, 1997). The option was made to interview members of the high administration, managers and operational level workers to gather a variety of perceptions. Even if Boyd (2001) suggests up to 10 participants to reach saturation and Creswell (1998) recommends interviews with up to 10 people for a qualitative study, 27 interviews were conducted, and as interviewees were selected two representatives of the hospital board, five managers in productive areas - the OR and the four areas related to it in the surgical scheduling process. (ambulatory, diagnosis and imaging center, laboratory, and inpatient units) and twenty knowledgeable senior employees representing these five areas, four for each area to cover the different steps in each process. The average duration of the interviews was 47 minutes, ranging from 20 to 93 minutes; All the interviews were audio recorded and, later, transcribed, amounting to 291 single-spaced pages. The data thus gathered was categorized using Qualitative Content Analysis. Each interview was read multiple times to search 
for indications of problems. Those were later assembled by similarity, generating 17 emergent categories, as presented on section 4.1. Each category had its frequency annotated (number of interviewers citing that type of issue) and was compared with field notes for triangulation. Document analysis relied on the hospital information and accounting systems to create a generic model for the flow of patients, analyze potential bottlenecks, and compile information about production performance and waiting lists.

Phase (ii) produced a technical report presenting the data gathered in Phase (i) and proposing the adaption of PPSC concepts to the hospital's processes. After the discussion and approval from the hospital's board, a working team was constituted to execute the project.

Phase (iii) begin with the creation of a PPSC sector in the hospital and the adaptation of PPSC concepts to the hospital's reality. The OR macro-flux was selected as initial scope, focusing on elective surgeries. After a learning phase, other processes were incorporated to the PPSC scope of action. Process analysis was carried out with the participation of the 20 previously interviewed employees in addition to the researchers. Weekly executive meetings ensured accountability of the project progress and adequate register of decisions and alternate routes of execution requested during this phase. Physical implementation included the definition of the area and the changes on the organizational structure and the operational processes to place the PPSC sector in operation. Efficiency and production indicators were defined and collected to monitor the new sector's performance and the changes in the patient flow. As well as indicators of quantity of patients on the waiting list and the average waiting time and indicators of operating expenses. Indicators of patient satisfaction and organizational climate among the operational team were measured at the beginning of the project and at the end. The indicators were collected monthly through the hospital's information system and discussed among the controllership team, projects' managers, and senior management. These indicators formed the basis for analyzing the action-research field results, being collected during six consecutive months of operation, after a first month of implementation.

Finally, Phase (iv) consisted in compiling the field and the literature data into the emergent framework for Planning, Scheduling and Control of Patient Flow (PSCPF). The framework was independently assessed by a group of experts not previously related to any steps of the research. We invited three senior managers from different hospitals, four technical experts (graduate-level professionals with 5+ years of work experience in the healthcare sector) and four academic scholars (researchers with 10+ years of experience and indexed publications in PPSC and healthcare processes). Eight of these experts (two hospital managers, three technical experts and three academic representatives) accepted to participate on the assessment process and provided their feedback and suggestions, acknowledging the proposed framework as suitable to provide support in mitigating the patients' flow problems previously identified.

The basis for the data analysis in the research was mostly qualitative, although demand, capacity and services historical data have been used for quantitative analysis in specific cases. The complexity of the context and particularities of the system in question may have influenced the results in the short term, as expected in studies of an interpretive nature. However, these limitations do not interfere with the goal of discussing the concepts of PPSC in critical processes of healthcare organizations.

\section{PSCPF framework proposal, implementation and evaluation}

\subsection{Situational diagnosis}

The overall process related to elective cirurgical patients was mapped and the data was compiled into a value stream representation. The process started at the patient's first appointment with a specialist and ended at his/her discharge. Throughout the process, the existing points of planning and control were identified and analyzed. For instance, in the OR, this involved defining service capacity, organizing procedures based on available staff and supplies, purchasing management and the patient's clinical condition.

The absence of integrating mechanisms to manage this flow occasioned losses similar to those indicated in Table 1, especially flawed management of waiting lists, unintegrated departments (or information silos), and scheduling errors. Each department had an autonomous scheduling sector that worked according to its routines and the visibility of local demand. This behavior is typical in the context of independent services, which creates the restrictions of intermediate capacity and unmanaged waiting lists (Lemos et al., 2013). Unable to analyze the patient flow in a systemic way, each sector would make decisions to maximize its local operation. These decisions were sometimes refereed in the absence of understanding of other broader restrictions of the hospital flow, particularly the flow of elective chirurgical patients.

The interviews' analysis generated 17 categories, as presented in Table 2. The categories are not isolated and contribute to one another. The interrelation of problems can be illustrated by this example: "[...] without knowing the 
Table 2. Summary of the analysis of the 27 interviews.

\begin{tabular}{lcc}
\hline \multicolumn{1}{c}{ Main Problems Raised at the Interviews } & Frequency of occurrence & In-field observation \\
\hline Unawareness of waiting lists & 23 & Yes \\
Substandard control on costs and payment of procedures & 17 & Yes \\
Constant errors in scheduling & 15 & Yes \\
Losses of documents and surgery reports & 14 & Yes \\
Several areas making confirmation contact with patients & 14 & Yes \\
Lack of preoperative care programming & 14 & Yes \\
Reworking in surgeries authorization & 11 & Yes \\
Unpredictability of dates to patients & 10 & Yes \\
Surgery scheduling ordered and controlled only by surgeons & 9 & Yes \\
No long-term planning & 8 & Yes \\
High absenteeism due to flawed contact with patients & 7 & Yes \\
Decentralization of scheduling & 7 & Yes \\
ldleness in programming appointments and surgeries & 6 & Yes \\
Obsolete production indicators & 6 & Yes \\
Disintegration of the scheduling staff & 5 & Yes \\
High number of ombudsmen and judicial orders & 5 & Yes \\
Low connection with the purchase/supply sector & 3 & Yes \\
\hline
\end{tabular}

waiting lists and having the schedules controlled only by the surgeons, many scheduling errors occurred, generating multiple contacts with patients, problems in the preoperative process and unpredictable dates for patients".

The problems found in the interviews are similar to those found in the literature (Table 1), revealing the need for further analysis and structuring of management models for the resolution of such problems in the healthcare context. It should be noted, however, that these are operation management problems. These findings were synthesized and presented in a technical report to the hospital board.

\subsection{PSCPF framework proposal}

Based on the data gathered on Phase (i) and the technical report produced in Phase (ii), a PPSC sector was proposed to the hospital and PPSC concepts began to be adapted to the hospital's reality, considering the patients' flow. Typically, the elective chirurgical patient's flow occurs as follows: specialist appointment; requesting of initial medical tests; either scheduling exams or putting the patient on a waiting list; carrying out the initial exams; scheduling the return appointment or putting the patient on the waiting list for a second appointment; return appointment; verifying the need for surgery; requesting preoperative exams; scheduling admission or waiting list for admission; preoperative examinations; scheduling a second return appointment or waiting list; issuing the surgery request; request authorization; surgery scheduling or waiting list; confirmation call to the patient; and admitting the patient to the OR on the day of surgery.

Several waits may arise during this flow, mostly due to the complexity of process; the lack of visibility of utilization levels among sectors; the excessive use of resources due to repeated or unnecessary tests, including overproduction due to test validity deprecation caused by excess patient's waiting; and inefficient services' synchronization and prioritization. Externalities also may arise, such as logistic problems. In Brazil, it is common that smaller towns send groups of patients to be attended in hub hospitals in larger cities, causing peaks of patient inflow, as well as patients loosing scheduled appointments due to the logistic restrictions. In addition, this dynamic generates patients' no-show, due to long waiting times between the flow stages: patients, in particular elderly ones, may forget appointments scheduled for months ahead, die, loose interest, or simply seek alternative treatment in other healthcare providers without informing their change of condition.

These problems are essentially similar to those studied and treated by the discipline of PPSC. According to Lustosa et al. (2008) PPSC, in manufacturing, must operate at three different levels: strategic, tactical and operational. Being the strategic level focused on capacity planning and management according to demand, the tactical level responsible for defining the product mix to be programmed in the medium term according to the resources and variables existing in the system, and the operational level responsible for the production execution in the short term, controlling the flow, inventories and day to day issues.

Considering the depicted context, the adoption of PPSC concepts lead to the proposition of three articulated operative centers to manage the patient's flow. The three centers compose the Planning, Scheduling and Control of Patient Flow (PSCPF) sector. The proposed functions for each center were: 
i. the strategic Planning and Control Center is responsible for analyzing information to be used by upper management in decision-making. Its functions include: managing demand and patient waiting-lists; planning capacity and services-provision; planning materials' supply (including orthoses, prostheses and special materials which are mandatory inputs for surgeries in specialties such as traumatology and cardiovascular surgery); controlling efficiency and production indicators; and internal auditing the sector of PSCPF, to indicate and fix flaws in the administrative process;

ii. the tactical and operational Scheduling Center is responsible for scheduling appointments, exams and surgeries; implementing policies for the better use of the OR and other related sectors; managing budget and materials purchases, including associated authorization processes; and scheduling preoperative exams (and beds, if necessary), such as laboratory test, echocardiogram, x-ray and tomography;

iii. the operational Confirmations and Support Center is responsible for performing standardized patient confirmations; avoiding no-shows and cancellations due to inappropriate or lack of preparation; performing ex-post-facto satisfaction surveys; adjusting routinely agenda events. The main goals of this center are to absorb the effects of natural system fluctuations without disturbing other centers' operations, and to provide support for the demands of other areas related to PSCPF.

These three centers permeate the strategic, tactical, and operational levels in the hospital and are summarized in Figure 2.

To perform the activities proposed to each center, we suggested a set of roles and functions (presented in Table 3) based on the literature review and field data. The team profile was conceived to be multidisciplinary, involving people with administrative and healthcare training, as a basis for the proper operation of the sector and a better flow of care lines.

The structure of the PSCPF also considered the flow identified in both the planning phase and the studied hospital context, as well as was based on the following premises: (i) the sector should monitor the demand

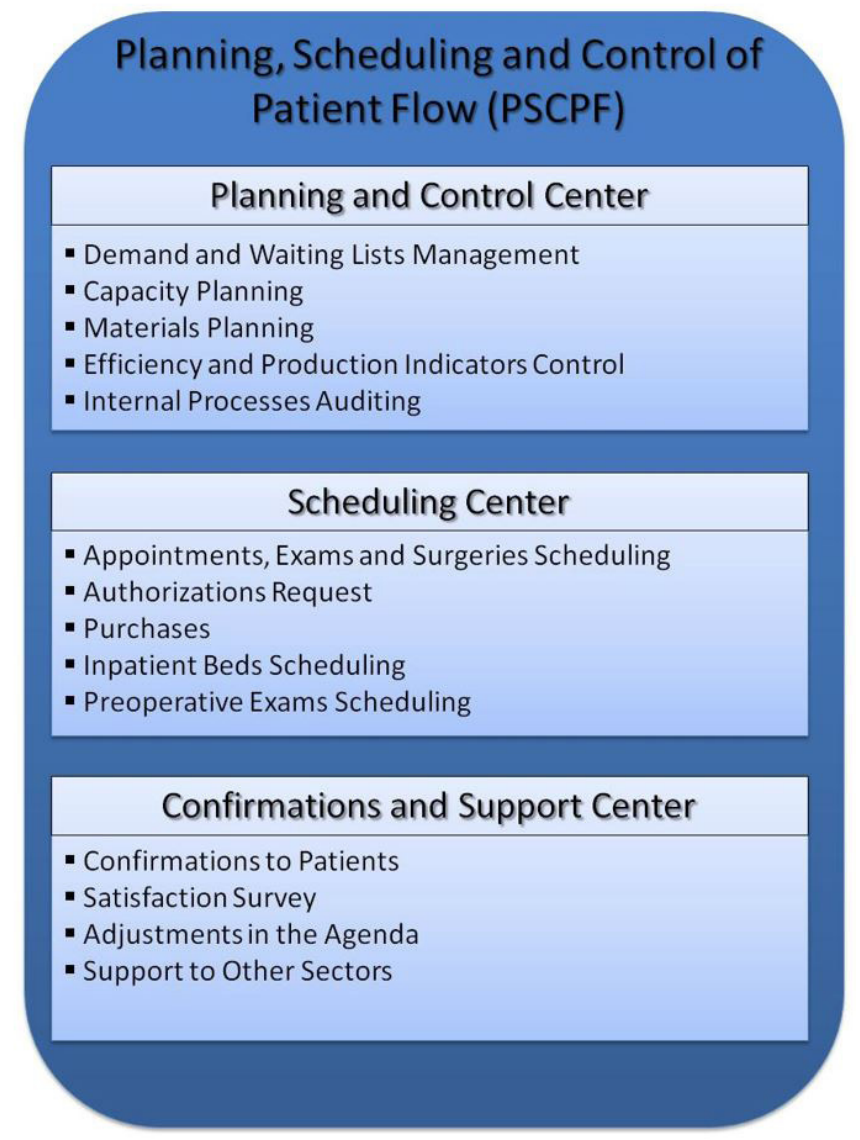

Figure 2. Proposed Framework for PSCPF Management. 
Table 3. Structure and functions for the PSCPF operation.

\begin{tabular}{|c|c|c|c|}
\hline Center & Position & Function & Source \\
\hline \multirow[t]{8}{*}{ Planning and Control } & \multirow[t]{4}{*}{ PSCPF Supervisor } & \multirow{4}{*}{$\begin{array}{l}\text { Supervise the PSCPF sector, managing the flow } \\
\text { of elective patients, monitoring efficiency and } \\
\text { production indicators along with team leadership } \\
\text { in achieving the goals set by upper management. }\end{array}$} & Field data, Ribeiro (1993) \\
\hline & & & Spagnol \& Ferraz (2002) \\
\hline & & & Pires et al. (2010) \\
\hline & & & Rechel et al. (2010) \\
\hline & Demand Analyst & $\begin{array}{l}\text { Analyze the demand for appointments, return } \\
\text { appointments, exams and surgeries, along with } \\
\text { waiting lists for specialties' care lines. }\end{array}$ & Cima et al. (2011) \\
\hline & Capacity Analyst & $\begin{array}{l}\text { Analyze the production capacity (supply) of the } \\
\text { involved sectors and propose adjustments for } \\
\text { meeting demand in an equitable fashion. }\end{array}$ & Conill et al. (2011) \\
\hline & Materials Analyst & $\begin{array}{l}\text { Analyze and program the need for materials, } \\
\text { orthoses, prostheses and special materials } \\
\text { according to demand and capacity planning, } \\
\text { making connections with the supplies and } \\
\text { involved areas. }\end{array}$ & LaGanga (2011) \\
\hline & Administrative Auditor & $\begin{array}{l}\text { Audit the sector's internal processes to identify } \\
\text { errors and daily fixes, thus avoiding gaps with } \\
\text { subsequent processes. }\end{array}$ & Lemos et al. (2013) \\
\hline \multirow[t]{8}{*}{ Scheduling } & \multirow[t]{3}{*}{ Scheduling Analyst } & \multirow{3}{*}{$\begin{array}{l}\text { Responsible for medium- and short-term } \\
\text { scheduling of exams, appointments and } \\
\text { surgeries and the programming required for their } \\
\text { realization. }\end{array}$} & Field data, Ribeiro (1993) \\
\hline & & & Spagnol \& Ferraz (2002) \\
\hline & & & Pires et al. (2010)) \\
\hline & Scheduling Assistant & $\begin{array}{l}\text { Provide administrative support to the Scheduling } \\
\text { Analyst in weekly and daily programming. }\end{array}$ & Rechel et al. (2010) \\
\hline & Authorizations Assistant & $\begin{array}{l}\text { Responsible for the organization and } \\
\text { authorization request for procedures with health } \\
\text { insurance plans and the Brazilian Unified Health } \\
\text { System. }\end{array}$ & Cima et al. (2011) \\
\hline & Purchaser & $\begin{array}{l}\text { Responsible for the realization of budgets and } \\
\text { materials purchases requested in accordance with } \\
\text { scheduling procedures. Direct connection with } \\
\text { supplies and Materials Analyst. }\end{array}$ & Conill et al. (2011) \\
\hline & Inpatient Beds Assistant & $\begin{array}{l}\text { Control and program the utilization of inpatient } \\
\text { beds in the recovery room and/or inpatient } \\
\text { units so that the overall patient flow is planned; } \\
\text { monitor the movement of scheduled patients. }\end{array}$ & LaGanga (2011) \\
\hline & Flow Nurse & $\begin{array}{l}\text { Program and control the flow of patients in the } \\
\text { sector, along with the realization of preoperative } \\
\text { tests, which are programmed in accordance with } \\
\text { protocols and waiting lists. Direct contact with } \\
\text { medical staff to resolve cases. }\end{array}$ & Lemos et al. (2013) \\
\hline \multirow[t]{8}{*}{ Confirmations and Support } & \multirow[t]{7}{*}{ Service Agent } & \multirow{7}{*}{$\begin{array}{l}\text { Make confirmation call to the patient related to } \\
\text { his schedule and initial instructions related to } \\
\text { his or her procedures; make calls to assess user } \\
\text { satisfaction after service. }\end{array}$} & Field data, Ribeiro (1993) \\
\hline & & & Spagnol \& Ferraz (2002) \\
\hline & & & Pires et al. (2010) \\
\hline & & & Rechel et al. (2010) \\
\hline & & & Cima et al. (2011) \\
\hline & & & $\begin{array}{l}\text { Conill \& Giovanella; Almeida } \\
\text { (2011) }\end{array}$ \\
\hline & & & LaGanga (2011) \\
\hline & Administrative Clerk & $\begin{array}{l}\text { Support service agents in administrative tasks } \\
\text { and routine adjustments; support other sectors in } \\
\text { need of patient information and/or defined flows. }\end{array}$ & Lemos et al. (2013) \\
\hline
\end{tabular}

(overall and internal), plan the patient flow according to the hospital productive capacity, schedule each flow in the organization, and control the flow of patients according to the established schedule; (ii) the sector should interact with the Supply Chain sector to schedule the necessary materials according to the scheduled services.

\subsection{PSCPF framework implementation and refinement}

The implementation took the form of a seven-month pilot project to refine the framework and evaluate the results of the created sector. Data gathered during this time revealed the PSCPF team manages an average of 11,000 elective appointments and 600 elective surgeries each month resulting in a monthly workload of 
approximately 200 requests of materials, 600 procedure authorizations, 3,000 pre-operative exams, and 15,000 confirmation calls, in addition to other secondary demands such as managing 4,000 patients on the waiting list for surgery, and an uncertain amount of thousands of patients waiting for a subsequent consultation (due the absence of well-defined listing and control).

Initially, based on the volume of activities mapped, the proposed processes (as in Figure 2) and functions (as in Table 3), the PSCPF team-size was estimated as 22 employees, divided as in Table 4. Fourteen employees who performed functions that had been merged into PSCPF would be relocated, nevertheless the proposed plan suggested hiring 8 new employees to the new sector, to follow the premises of knowledge domain and a multi-disciplinary team. The total team's salary cost was estimated at U\$ 186,500.00 annually, representing an increase of U\$83,000.00 in this expense. The hospital's board consider the hiring too expensive and cumbersome for a pilot project, due to the bureaucratic processes to be fulfilled. Considering this limitation, the structure and functions proposed were redistributed among the relocated employees. The relocated team was divided as presented in Table 4. The PSCPF sector was physically located at the hospital outpatient clinic, a location that facilitated the medical staff's movement, scheduling and communication during their appointment hours. Implementation and team stabilization took one month.

Table 4. Structure and functions for the PSCPF operation.

\begin{tabular}{cccc}
\hline Area & Position & Proposed Staff & Implemented Staff \\
\hline Planning and Control Center & PSCPF Supervisor & 1 & 1 \\
& Demand Analyst & 1 & 2 \\
& Capacity Analyst & 1 & - \\
& Materials Analyst & 1 & 1 \\
& Administrative Auditor & 1 & 3 \\
& Scheduling Analyst & 3 & 1 \\
& Scheduling Assistant & 3 & 1 \\
& Authorizations Assistant & 2 & 1 \\
& Purchaser & 1 & 3 \\
Total Staff & Inpatient Beds Assistant & 1 & 1 \\
& Flow Nurse & 3 & 1 \\
\hline
\end{tabular}

With the team assembled, the processes related to the PSCPF started their design according to the proposed framework (Figure 2) with a focus on planning, scheduling and control of patient flow, and managing confirmations to patients. The team chosen for the sector was accommodated in a single workplace to facilitate communication. And every day the Project Manager prepared a daily round for employees to adapt to the new processes.

\subsection{PSCPF framework evaluation}

After the implementation of the PSCPF sector, done in one month, data were collected and monitored for six months, using direct observation, manual registers, inputs from the hospital's information system, and perceptions from collaborators and managers gathered through focus groups and informal interviews. The internal assessment of the project, namely the changes in structure and processes, was carried out by the hospital board, based on waiting list indicators, preoperative costs, and the integration and communication of the staff before and after the implementation of the project.

After the monitoring period of six months, the framework was adjusted to represent small changes implemented during the monitoring period and presented to a group of specialists. Their feedback and inputs regarding viability and consistency were used to refine the framework, resulting in the scheme presented in Figure 3.

The hospital board also assessed and accompanied the PSCPF framework evolution, prior and during the intervention stage. The main advantages and benefits pointed out by specialists and the hospital board are the proposal's innovativeness and focus on results; the understanding of the need of an adequate patient-flow planning and control; and the potential of cost savings. In particular, the framework design brought together hospital's sectors and collaborators who, however had been previously working on patient flow, were used to do it in an uncollaborative and disjoint manner. 


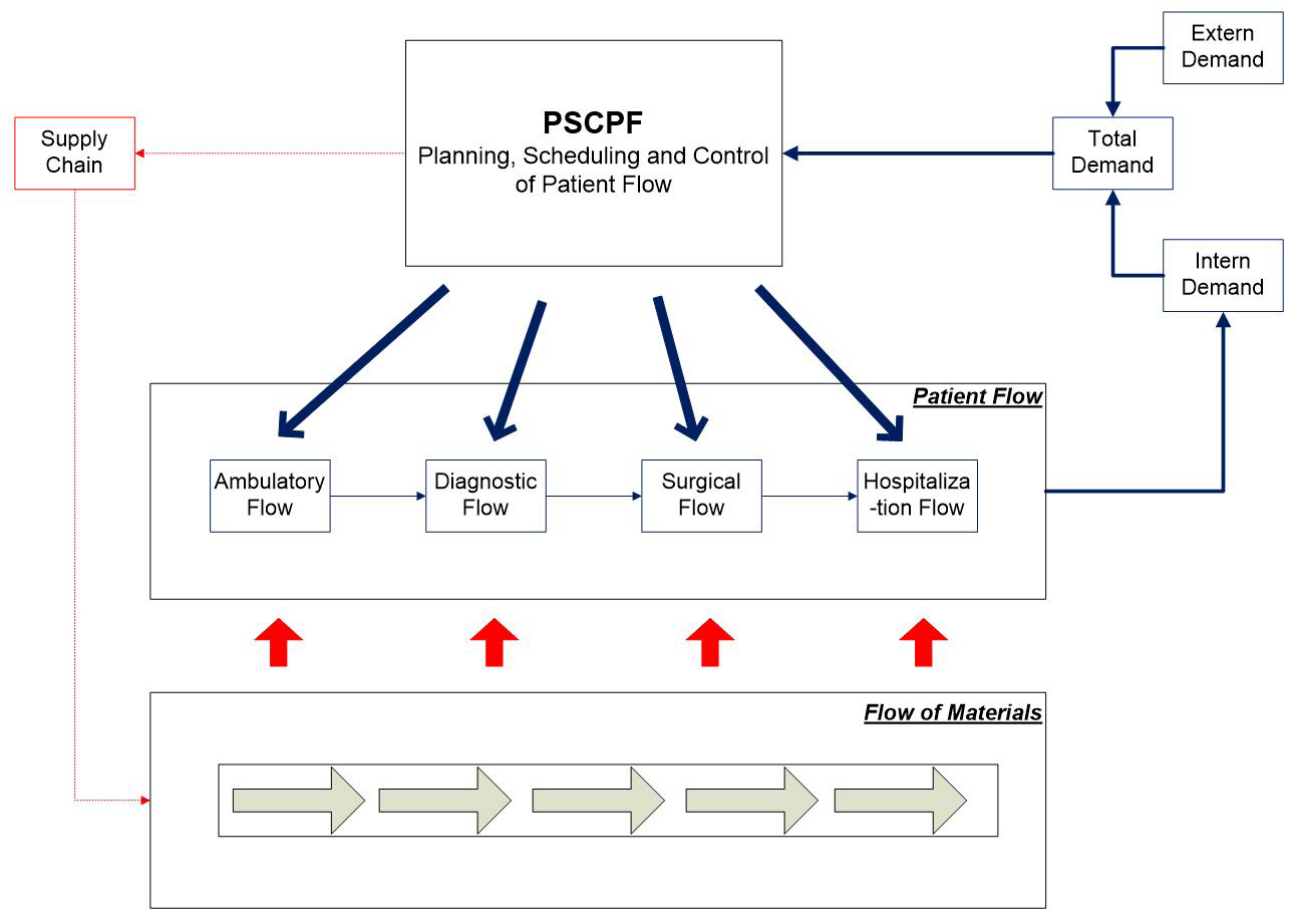

Figure 3. Scheme of the process.

Data gathered in the monitoring phase (six months) through indicators, focus groups and informal interviews analyzing key project indicators and comparing the previous panorama and after the project about patient lists, OR efficiency, and cost operating sector, pointed to the following results: (i) a 54\% reduction in the waiting list (number of patients) for clinic appointments; (ii) a 46\% reduction in the waiting list for surgical appointments (number of patients); (iii) annual hard savings of U\$ 182,000.00 in triage, appointment scheduling, preoperative exams and rescheduling costs.

In a qualitative and empirical way, through critical analysis meetings with the hospital board during the implementation of the new structure, there were references to the following improvements, which are expected to be sustained in the long term: (i) facilitated communication and greater integration of the multidisciplinary team; (ii) improving work relationships and the organizational climate; (iii) increased patient and employee satisfaction with the surgery scheduling process; (iv) reduction of patient complaints and general attendant stress; and $(v)$ reducing staff stress on patient safety issues related to the control of waiting lists. These improvements may be measured with specific and systemic criteria, that were not part of this study due to time limitations.

These results were presented to the hospital board, which approved the sector as a formal area within the organization, establishing a cost center for the PSCPF management. This administrative decision allowed more autonomy for the sector in the hospital's administrative and governance context. This concluded the field phase of the action-research, showing the feasibility and potential benefits of a PSCPF sector in a hospital setting.

\section{Discussion}

From an analytical perspective, the PSCPF is the adaption of PPSC concepts to the hospital context. Considering the nature of the issues under analysis, performance improvement is expected. Nevertheless, contribution is perceived in the sense of cultural appropriation of such OM concepts in the healthcare environment. The healthcare experts and hospital managers who participated during the research reinforced such perception as "innovative to the sector, at least in developing countries", though no registered academic evidence is sufficient to corroborate such terms. Even so, results obtained along the pilot operation allow to establish a transition function from Table 1 to the outcomes presented in Table 5.

The analysis of Table 5 allows inferring that many of the evidenced improvements lay in the foundation of $\mathrm{OM}$ and production systems management. They could be obtained through different approaches, such as Lean thinking, and continuous improvement methods and tools (process mapping, visual management, standardized 
Table 5. Transition function associated to the evidences of the PSCPF framework implementation.

\begin{tabular}{|c|c|c|c|}
\hline Perspectives & Problems & Authors & Evidences from the PSCPF implementation \\
\hline \multirow[t]{6}{*}{ Planning } & $\begin{array}{l}\cdot \text { Low production capacity in relation to } \\
\text { demand }\end{array}$ & LaGanga (2011) & - Reduction of idleness and staff absenteeism \\
\hline & - Flawed management of waiting lists & Lemos et al. (2013) & - Systemic management of waiting lists \\
\hline & - Lack of production and quality goals & Lemos et al. (2013) & - Assistance in solving ombudsman issues and court orders \\
\hline & - Disordered demand flow & Pires et al. (2010) & - Reduction of preoperative costs \\
\hline & · Unintegrated departments (silos) & Conill et al. (2011) & - Improved elective-patient flow speed and control \\
\hline & & Rechel et al. (2010) & - Integrated multidisciplinary team \\
\hline \multirow[t]{6}{*}{ Scheduling } & - Scheduling errors & LaGanga (2011) & $\begin{array}{l}\text { - Standardization of the materials and orthoses, prostheses } \\
\text { and special materials request }\end{array}$ \\
\hline & $\begin{array}{l}\text { Failure in the standardization of } \\
\text { procedures and time }\end{array}$ & Pires et al. (2010) & - Standardized scheduling \\
\hline & - Wrong information to the patient & LaGanga (2011) & - Standardized and expedite authorizing procedures \\
\hline & $\begin{array}{l}\text { - Under/Over-utilized structures and delayed } \\
\text { processes }\end{array}$ & $\begin{array}{l}\text { Spagnol \& Ferraz } \\
\quad(2002)\end{array}$ & - Provision of predictable dates to patients \\
\hline & & & - Reduction of waiting lists for appointments \\
\hline & & & - Distribution of surgical rooms according to demand \\
\hline \multirow[t]{4}{*}{ Control } & - Lack of no-show control and cancellations & LaGanga (2011) & - Standardized and controlled confirmation calls \\
\hline & - Flawed efficiency control & Ribeiro (1993) & - Efficiency and production control \\
\hline & - Limitations in information management & Cima et al. (2011) & - Organization of documents and reports \\
\hline & - Lack of key performance indicators & & - Structured indicators' system in the process \\
\hline
\end{tabular}

operations and documents, control charts, and efficiency indicators, among others). Nevertheless, such approaches would probably drive the healthcare organization toward the adoption of a PPSC structure or decentralized flow management approaches (e.g. kanban systems), due to the isomorphism of concepts and practices registered in the body of knowledge of OM.

Team integration is, nevertheless, critical in the sense of the outcomes identified in this action-research. Even considering the use of a lean team, team integration would be both a necessary condition, and a desired outcome of the implementation process. Hospitals still are managed through a departmental structure, with lack of process and OM understanding. As a consequence, information silos and "over-the-wall" behavior are still frequent in hospital organizations. The creation of a PSCPF sector compels the hospital organization to establish a multidisciplinary team who focuses the patient, or, in OM technical terms, the subject of the value-addition process. By focusing on the patient flow, such team cares about the process of the patient though the hospital structure, thus increasing the chances of providing an efficient and effective service to this patient while reducing unintended/unnecessary use of resources and inputs. In addition, the PSCPF framework implementation may be done through a sector in the hospital structure (as in the action-research reported), being potentially less difficult to incorporate to a hospital's managerial culture than other OM approaches such as kanban systems. This does not mean, nevertheless, it will produce better results than other approaches such those proposed by Lean Healthcare.

The adaptation of OM concepts as PSCPF in healthcare processes improve organizational planning and healthcare flow, establishing effective and concrete conditions for sustaining other healthcare management concepts and strategies, such as clinical care lines. Clinical care lines provide safe and guaranteed healthcare flows that enable the patient to meet his healthcare needs. It represents the patient's route through a healthcare network, being run not only by established protocols but also by service management flows and improved work processes. In addition, as in other production systems, clinical care lines may increase productivity in a coordinated manner, eliminating flow inefficiencies in accordance with variations in demand.

Finally, this is an emergent framework for PSCPF. Further studies are needed on a wider range of hospitals and organizational environments to establish a robust operational framework, particularly regarding recommendations on the roles and the number of employees on each proposed center. The implementation of a continuous improvement culture in the hospital administrative context would also be addressed as a pressing concern, given the possibility of losing the improvements gained from a PSCPF implementation.

\section{Conclusion}

Although different countries have different health systems, hospitals are affected by some universal problems: predictable errors that lead to operational inefficiencies, complications and death of patients. Such problems shall 
be solved considering: the focus on improving patients' assistance; each organization context; and the adaption of $\mathrm{OM}$ concepts to healthcare organizations. Production Engineering, as an applied science, provides tools for improving care delivery to the patient through the redesign, planning and control of the flow of processes.

This study analyzed the feasibility of using the PPSC concepts in a hospital setting based on action research. To that end, it proposed a framework for structuring a PSCPF sector for the flow of elective patients of a large Brazilian university hospital. After implementing the sector based on the proposed framework, the organization obtained results considered as important in managing the flow of elective patients, including a significantly reduced waiting lists, improved scheduling of preoperative exams, reduced waste-related costs, and greater production and efficiency control of productive areas. The understanding and proper implementation of the concept of PSCPF contributed to mitigate problems related to capacity (supply) management, unawareness of demand and waiting lists between sectors, scheduling errors, and the provision of false information to patients resulting from the disconnection between the various areas of the hospital.

This is an interpretive study; therefore, it produces an emerging proposal of PSCPF. Future studies are suggested both to apply this framework in other hospital organizations of various sizes and to compare the achieved results for validating and refining the proposed model. To the extent of the produced results and to the extent that the search for references was possible, there is no similar model in the Brazilian hospital network, especially in the public network, which is constantly pressed by demand that greatly exceeds capacity. The integration of this concept in studies related to the production efficiency of appointments and surgery to studies on the epidemiology (demand) of elective services, along with the leveling of the production capacity of medical services in relation to their demand, are also suggested. The integration of these approaches tends to generate profitable, more robust solutions, as recognized in the field of operations management. Another suggestion for future academic research and practical applications would be to create a standardized information system in accordance with the PSCPF processes for the automated improvement of the sector, thus generating greater speed in scheduling, waiting-list control and operational indicators.

\section{References}

Associação Brasileira de Engenharia de Produção - ABEPRO. (2008). Áreas e sub-áreas de Engenharia de Produção. Rio de Janeiro: ABEPRO. Retrieved in 2015, November 18, from http://www.abepro.org.br/interna.asp? $p=399 \& m=424 \& s=1 \& c=362$

Boyd, C. 0. 2001. Phenomenology the method. In P. L. Munhall (Ed.), Nursing research: a qualitative perspective (3rd ed., pp. 93-122). Sudbury: Jones and Bartlett.

Butler, T. W., Leong, G. K., \& Everett, L. N. (1996). The operations management role in hospital strategic planning. Journal of Operations Management, 14(2), 137-156. http://dx.doi.org/10.1016/0272-6963(95)00041-0.

Cardoen, B., Demeulemeester, E., \& Beliën, J. (2010). Operating room planning and scheduling: a literature review. European Journal of Operational Research, 201(3), 921-932. http://dx.doi.org/10.1016/j.ejor.2009.04.011.

Cardoso, J. G., \& Erdmann, R. H. (2001). Planejamento e controle da produção na gestão de serviços: o caso do Hospital Universitário de Florianópolis. In Anais do XXI Encontro Nacional de Engenharia de Produção. Rio de Janeiro: ABEPRO.

Cima, R. R., Brown, M. J., Hebl, J. R., Moore, R., Rogers, J. C., Kollengode, A., Amstutz, G. J., Weisbrod, C. A., Narr, B. J., \& Deschamps, C. (2011). Use of lean and six sigma methodology to improve operating room efficiency in a high-volume tertiary-care academic medical center. Journal of the American College of Surgeons, 213(1), 83-92. http://dx.doi.org/10.1016/j.jamcollsurg.2011.02.009. PMid:21420879.

Conill, E. M., Giovanella, L., \& Almeida, P. F. (2011). Listas de espera em sistemas públicos: da expansão da oferta para um acesso oportuno? Considerações a partir do Sistema Nacional de Saúde espanhol. Ciencia \& Saude Coletiva, 16(6), 2783-2794. http:// dx.doi.org/10.1590/S1413-81232011000600017. PMid:21709976.

Creswell, J. W. (1998). Qualitative inquiry and research design: choosing among five traditions. Thousand Oaks: SAGE.

Drupsteen, J., van der Vaart, T., \& Pieter van Donk, D. (2013). Integrative practices in hospitals and their impact on patient flow. International Journal of Operations \& Production Management, 33(7), 912-933. http://dx.doi.org/10.1108/1JOPM-12-2011-0487.

Dutra, F. A. F., \& Erdmann, R. H. (2007). Análise do planejamento e controle da produção sob a ótica da Teoria da Complexidade. Production, 172), 407-419. http://dx.doi.org/10.1590/S0103-65132007000200015.

Fernandes, F. C. F., \& Santoro, M. C. (2005). Avaliação do grau de prioridade e do foco do planejamento e controle da produção (PCP): modelos e estudos de casos. Gestão \& Produção, 12(1), 25-38. http://dx.doi.org/10.1590/S0104-530X2005000100004.

Graban, M. (2009). Lean hospitals: improving quality, patient safety, and employee satisfaction. London: CRC Press.

Hart, S. L., \& Milstein, M. B. (2004). Criando valor sustentável. RAE Executivo, 3(2), 65-79. http://dx.doi.org/10.12660/gvexec. v3n2.2004.34820.

Hasle, P., Nielsen, A. P., \& Edwards, K. (2016). Application of lean manufacturing in hospitals: the need to consider maturity, complexity, and the value concept. Human Factors and Ergonomics in Manufacturing \& Service Industries, 26(4), 430-442. http://dx.doi. $\operatorname{org} / 10.1002 / \mathrm{hfm} .20668$.

LaGanga, L. R. (2011). Lean service operations: reflections and new directions for capacity expansion in outpatient clinics. Journal of Operations Management, 29(5), 422-433. http://dx.doi.org/10.1016/j.jom.2010.12.005.

Laugeni, F. P., \& Martins, P. G. (2005). Administração da produção. São Paulo: Saraiva. 
Lemos, M. S. A., Dias, E. C., de Miranda Fortes, N., \& Teixeira, M. G. (2013). 0 impacto do Projeto de Cirurgias Eletivas de Belo Horizonte sobre a fila de espera. Enfermagem Revista, 16(3), 159-174.

Lima, R. M., Dinis-Carvalho, J., Souza, T. A., Vieira, E., \& Gonçalves, B. (2021). Implementation of Lean in Healthcare environments: an update of systematic reviews. International Journal of Lean Six Sigma, 12(2), 399-431. http://dx.doi.org/10.1108/1JLSS-07-2019-0074.

Litvak, E., \& Bisognano, M. (2011). More patients, less payment: Increasing hospital efficiency in the aftermath of health reform. Health Affairs, 30(1), 76-80. http://dx.doi.org/10.1377/hlthaff.2010.1114. PMid:21209441.

Lustosa, L. J., Mesquita, M. A., \& Oliveira, R. J. (2008). Planejamento e controle da produção. Rio de Janeiro: Elsevier Brasil.

Paim, J. S. (2006). Planejamento em saúde para não especialistas. In G. W. S. Campos, M. C. S. Minayo, M. Akerman, M. Drumond Júnior \& Y. M. Carvalho (Eds.), Tratado de saúde coletiva (pp. 767-782). São Paulo: Hucitec.

Pedroso, M. C. (1999). Modelo de gestão do sistema de planejamento, programação e controle da produção. Revista de Administração da Universidade de São Paulo, 34(2), 55-71.

Pedroso, M. C., \& Corrêa, H. L. (1996). Sistemas de programação da produção com capacidade finita: uma decisão estratégica? Revista de Administração de Empresas, 36(4), 60-73. http://dx.doi.org/10.1590/S0034-75901996000400007.

Pires, M. R. G. M., Göttems, L. B. D., Martins, C. M. F., Guilhem, D., \& Alves, E. D. (2010). Oferta e demanda por média complexidade/SUS: relação com atenção básica. Ciência \& Saúde Coletiva, 15(Suppl. 1), 1009-1019. http://dx.doi.org/10.1590/S1413-81232010000700007. PMid:20640257.

Pontual, L. (2004). Uma análise crítica sobre as principais abordagens de PCP. In Anais do XXIV Encontro Nacional de Engenharia de Produção (ENEGEP). Rio de Janeiro: ABEPRO.

Porter, M. E. (2010). What is value in health care. The New England Journal of Medicine, 363(26), 2477-2481. http://dx.doi.org/10.1056/ NEJMp1011024. PMid:21142528.

Rechel, B., Wright, S., Barlow, J., \& McKee, M. (2010). Hospital capacity planning: from measuring stocks to modelling flows. Bulletin of the World Health Organization, 88(8), 632-636. http://dx.doi.org/10.2471/BLT.09.073361. PMid:20680129.

Ribeiro, H. P. (1993). O hospital: história e crise. Säo Paulo: Cortez.

Schwandt, T. A. (1997). Qualitative inquiry: a dictionary of terms. Thousand Oaks: SAGE.

Slack, N., Chambers, S., Harland, C., Harrison, A., \& Johnston, R. (1995). Operations management. London: Pitman.

Souza, T. A., Vaccaro, G. L., \& Lima, R. M. (2020). Operating room effectiveness: a lean health-care performance indicator. International Journal of Lean Six Sigma, 11(5), 987-1002. http://dx.doi.org/10.1108/1JLSS-12-2017-0141.

Spagnol, C. A., \& Ferraz, C. A. (2002). Tendências e perspectivas da administração em enfermagem: um estudo na Santa Casa de Belo Horizonte-MG. Revista Latino-Americana de Enfermagem, 10(1), 15-20. http://dx.doi.org/10.1590/S0104-11692002000100003. PMid:12080583.

Teixeira, C. F. (1999). Epidemiologia e planejamento de saúde. Ciência \& Saúde Coletiva, 4(2), 287-303. http://dx.doi.org/10.1590/ S1413-81231999000200005.

Vieira, F. S. (2009). Avanços e desafios do planejamento no Sistema Único de Saúde. Ciência \& Saúde Coletiva, 14(Suppl. 1), $1565-1577$. http://dx.doi.org/10.1590/S1413-81232009000800030. PMid:19750366.

Vollmann, T. E., William, L. B., Whybark, D. C., \& Jacobs, F. R. (2006). Sistemas de planejamento \& controle da produção para o gerenciamento da cadeia de suprimentos (S. Oliveira \& R. G. Banolas, Trans., 5th ed.). Porto Alegre: Bookman.

Welman, J. C., \& Kruger, S. J. (1999). Research methodology for the business and administrative sciences. Johannesburg: International Thompson.

Zäpfel, G., \& Missbauer, H. (1993). New concepts for production planning and control. European Journal of Operational Research, 67(3), 297-320. http://dx.doi.org/10.1016/0377-2217(93)90287-W. 